\title{
The Complementarity of Corporate IT Alignment and Business Unit IT Alignment: An Analysis of Their Joint Effects on Business Unit Performance
}

\author{
Magno Queiroz \\ Utah State University \\ magno.queiroz@usu.edu
}

\author{
Tim Coltman \\ University of Waikato \\ tcoltman@waikato.ac.nz
}

\author{
Paul Tallon \\ Loyola University Maryland \\ pptallon@loyola.edu
}

\author{
Rajeev Sharma \\ University of Waikato \\ rsharma@waikato.ac.nz
}

\author{
Peter Reynolds \\ MIT \\ preynold@mit.edu
}

\begin{abstract}
Alignment between IT and business strategy is a perennial challenge for IT executives, in part due to the evolving nature of organizational structure. In multi-business organizations (MBOs), a pressing issue for IT executives is how to improve the performance of each strategic business unit (SBU). In this paper we examine how IT alignment in MBOs affects SBU performance. We distinguish between IT alignment at the corporate and SBU levels and propose that these two types of IT alignment are complementary and exert joint effects on SBU performance. Two hypotheses related to these joint effects are developed and tested using data collected from an international survey of IT executives. Our findings indicate that complementarities between corporate IT alignment and SBU IT alignment enhance SBU performance. The primary contribution of this paper is explaining how different types of IT alignment in MBOs - individually and jointly - affect $S B U$ performance.
\end{abstract}

\section{Introduction}

The multi-business organization (MBO) structure is widely employed by organizations to accommodate globalization and business diversification [11, 32]. Oliver Williamson - Nobel Laureate and co-founder of transaction cost economics - dubbed the multibusiness or M-form organization the most significant innovation of the last century [49]. With the rise of the digital economy, increasing investments in information technology (IT) provided MBOs with the potential to exploit business synergies and utilize IT to coordinate activities across SBUs [42]. However, the MBO structure presents particular challenges for aligning IT with business strategy. For instance, the IT needs of the corporate unit and its SBUs can vary because of differences between corporate and SBU strategies [32, 47]. In addition, MBOs are building corporate IT platforms as a way to share IT resources and capabilities across the organization $[15,32,34] .{ }^{1}$ This allows SBUs to leverage both corporate and local IT to meet their IT needs. While prior literature has considered strategic IT alignment - i.e., the extent of congruence or fit between IT and business strategy from multiple perspectives $[4,9,36,48]$, it has yet to consider the unique challenges and effects of IT alignment in MBOs [10, 32].

It is well known that strategic IT alignment (hereafter IT alignment) can affect overall firm performance [e.g., 7, 26, 35]. For managers in MBOs, a pressing issue is how to improve the performance of each market-facing SBU competing in its own productmarket space [47]. Yet, despite significant progress in answering the question of how IT alignment affects firm performance, extant IT alignment research treats the corporate unit as a proxy for the whole organization [12]. As such, it does not account for differences between IT alignment at the corporate and SBU levels and how they relate to each other and to SBU performance. This is an important issue because individual SBUs, particularly those that contribute a large share of the firm's financial performance, can have a significant impact on the MBO's bottom line $[11,18]$.

The purpose of this study is to examine how different types of IT alignment in MBOs - individually and jointly - affect SBU performance. To do this, we distinguish between corporate IT alignment, defined as the congruence or fit between corporate strategy and the corporate IT platform, and SBU IT alignment, defined as the congruence or fit between SBU strategy and the SBU IT applications portfolio. In this way, we

\footnotetext{
${ }^{1}$ The term corporate IT platform refers to internal firm-wide platforms used to share IT capabilities rather than interfirm platforms that support innovation ecosystems.
} 
acknowledge the distinct and complementary roles of the corporate IT function and the IT function of SBUs [32]. MBOs can use a corporate IT platform to build IT support for global processes that are common across multiple SBUs (e.g., HR, legal, procurement, etc.). Individual SBUs can build their own IT portfolios to support more idiosyncratic and strategic activities. Hence, the IT support provided by the corporate unit and that provided locally by SBUs can be complementary. Drawing on the literatures on IT alignment $[8,10,32]$ and resource complementarities $[41,42,43]$, we propose and test a theory that argues that the two types of IT alignment in MBOs are complementary and that they have joint positive effects on SBU performance. Therefore, the focus of this paper goes beyond the impact of the main effects of corporate IT alignment or SBU IT alignment. Instead, we investigate the relatively unknown and underresearched impact of their joint presence (i.e., their interaction) on the performance of SBUs.

This paper contributes to the literature by examining complementarity effects of IT alignment in MBOs. Prior research has focused on explaining firm performance primarily in single segment / single line of business firms. In those firms, there is a single business strategy and all IT support is provided by the corporate unit [40]. Extending that view, we propose that SBU performance in MBOs is a function of complementarities between corporate IT alignment and SBU IT alignment. For practitioners, our study provides insights into how corporate management efforts to build IT platforms and improve alignment at the corporate level can impact SBU performance.

\section{Theoretical Development}

Extant literature has explored IT alignment from multiple perspectives in order to explain its effects on firm performance [31]. For instance, Chan et al. [7] investigate alignment between business strategy and IT strategy; Oh and Pinsonneault [26] focus on alignment between business strategy and the firm's portfolio of IT applications, while McLaren et al. [23] examine alignment between business strategy and IT capabilities. Despite marked progress in our understanding of the performance effects of IT alignment, researchers have stepped up calls for further research to investigate the nature and effects of IT alignment in MBOs [10, 32, 50].

\subsection{IT Alignment in MBOs}

While it is feasible for corporate units and SBUs to work independently - almost as if they were separate organizations with separate management structures and separate IT - the received view of MBOs stresses the intertwined relationships across SBUs and how corporate and SBU IT can capture scale and scope economies [27, 39, 42, 44]. The business strategy of the corporate unit delineates the boundary of the organization and the formal relationships between SBUs and the corporate unit. It is concerned with managing a portfolio of shared resources that can be employed by multiple SBUs. It is not unusual to find that the IT needs of processes such as HR, legal, procurement, and accounting are similar across SBUs even if the processes themselves vary across SBUs [47]. The optimal response in this case is to orchestrate IT support for these common SBUs' processes as a corporate-sponsored function.

Equally, the IT needs of primary processes such as logistics, operations, and customer support can vary across SBUs [47]. This occurs because SBUs have autonomy with respect to their business strategy and the unique IT resources needed to compete within their product-market spaces. Specifically, SBU business strategy specifies how an individual SBU will compete within its product-market space. It is then the responsibility of SBU IT managers to ensure that the local IT applications portfolio can support the SBU's idiosyncratic business activities.

In this context, tensions between SBUs and the corporate unit over investments in and control over IT and other assets need to be constantly managed to ensure alignment $[3,14,34,37,46]$. For example, the corporate unit can be tempted to assert control over its SBUs in order to optimize firm performance across its portfolio of SBUs, to minimize portfolio risk, and to achieve economies of scale $[1,15]$. In contrast, SBUs may try to retain some degree of autonomy and control over investing in resources they feel are necessary to optimize their individual performance rather than operating under corporate resource restrictions $[10$, 14].

As such, there is a counter-balancing dynamic at play in MBOs that suggests an omnibus IT alignment conceptualization cannot capture the different IT alignment challenges at the corporate and SBU levels. Prior research has focused on the alignment of firmwide strategy with IT. While this approach has produced some rich insights, it does not account for potential complementarity effects of two different types of IT alignment that occur in an MBO context: corporate IT alignment and SBU IT alignment.

A high degree of corporate IT alignment will likely exist when the corporate unit is able to use IT including shared IT - to manage its portfolio of SBUs and the relationships between these SBUs. The case of the Commonwealth Bank of Australia (CBA) 
illustrates the importance of building corporate IT alignment. In the mid-2000s, CBA's corporate strategy was focused on customer service and in building a single view of customers across its market-facing SBUs that included investment management, insurance, retail banking, and corporate banking. In order to realize this strategy, CBA had to first confront multiple and often distinct IT systems that were used across the organization to check customers' information. In the absence of integrated or shared systems, employees in different SBUs were regularly unaware of products and services customers had with other parts of the bank. To resolve this issue, CBA made significant investments in creating a corporate IT platform that would align with the corporate strategy. The IT platform facilitated a single customer identifier, tracking of customers across channels, multi-channel access, and shared electronic customer records [32].

However, IT alignment at the corporate level does not preclude the necessity for building IT support to meet idiosyncratic SBU needs that allow them to compete effectively within their specific markets [5, 10]. A high degree of SBU IT alignment will likely exist when the SBU IT portfolio meets those needs [5]. In MBOs, as argued earlier, SBUs provide a certain level of IT to support their unique business needs. For instance, CBA's retail bank and insurance SBUs were able to improve local IT alignment - outside any corporate IT platform - by building IT applications to support the sale and processing of home loans, commercial loans, and to cross-sell insurance to customers with loans [32].

Hence, the impacts of corporate IT alignment and SBU IT alignment can be complementary given that the focus of the corporate unit is to build IT support for common activities across the organization, thus freeing SBUs to build IT support for idiosyncratic activities needed to compete in local markets. Next, we discuss the concept of complementarity to ground our study of IT alignment in MBOs.

\subsection{Complementarity and Performance}

The economic theory of complementarities argues for the benefits of coherent and holistic resource investments. It proposes that superior performance payoffs depend on internal coherence between complementary organizational resources and activities [24, 25, 28]. Complementarity occurs when "doing more of one thing increases the returns of doing more of another" [24, p. 181]. ${ }^{2}$ Thus, complementary

\footnotetext{
${ }^{2}$ Formally, let $f(x, y, z)$ be a payoff function where $z$ is a vector of variables related to the payoff. The variables $x$ and $y$ are complements if $f$ has the property: $f(x ”, y ”, z)-f$
}

resources and capabilities can have mutually supportive performance impacts [43].

Prior research indicates that complementarities can generate significant performance benefits. For example, Zhu [51] finds that complementarity of IT infrastructure and e-commerce capability affects firm performance. Similarly, Song et al. [38] argue that integrating marketing-related capabilities and complementary IT capabilities leads to better performance outcomes because such integration reconfigures existing competencies, reduces resource deficiencies, and generates new opportunities for leveraging resources.

A common theme in the literature investigating complementarities is the performance benefit that accrues when MBOs share capabilities and use common management processes across its SBUs [41, 42, 43]. For example, Tanriverdi [42] investigates the performance impacts of IT relatedness, which refers to the use of corporate-wide IT management processes and common policies for managing IT infrastructure components. He finds that complementarities among common IT infrastructure policies and corporate-wide IT management processes enhance the performance of MBOs.

In line with this body of research, we propose that organizational efforts to build IT alignment at the corporate level can complement the efforts of individual SBUs to build IT alignment locally via their own IT portfolios. Below, we develop our hypotheses related to the complementarity effects of IT alignment in MBOs.

\subsection{Complementarity Effects of Corporate IT Alignment and SBU IT Alignment}

Corporate IT alignment is an enabler of overall firm performance [8] and can also impact the performance of market-facing SBUs $[5,23]$. We propose that its performance benefits to SBUs are amplified when corporate IT alignment is complemented by a high degree of SBU IT alignment. When corporate IT alignment is high, corporate managers will be well positioned to build IT support for activities that are common across SBUs and to complement SBUs' own efforts to build local IT support for idiosyncratic activities [10, 32]. This allows SBUs to more effectively address what is unique to them to compete effectively in their product-markets [34, 47].

$\left(x^{\prime}, y^{\prime \prime}, z\right) \geq f\left(x^{\prime \prime}, y^{\prime}, z\right)-f\left(x^{\prime}, y^{\prime}, z\right)$ for all $x^{\prime \prime}>x, y ”>$ $y^{\prime}$. Thus, complementarity occurs when increasing the variable $x$ from its lower level $x$ ' to the higher level $x$ " is more beneficial when $y$ is at the higher level $y$ " than at the lower level $y^{\prime}[24,28]$. 
However, because of complementarities and path dependencies between corporate-wide IT investments and local SBU investments, corporate IT alignment alone may not necessarily lead to improved SBU performance. Since a large part of the corporate strategy in MBOs is meant to coordinate activities across SBUs and to maintain a portfolio of SBUs that deliver optimal firm performance [42], the primary goal of corporate IT alignment is to support corporatewide strategic goals rather than individual SBU needs. If SBUs fail to build IT support for their local needs, SBU performance could be adversely impacted due to poor SBU IT alignment and the lack of corporate IT capabilities to support idiosyncratic SBU activities [32].

On the other hand, since corporate IT platforms are designed to provide support for shared business activities, a base level of IT support for new SBU initiatives could already exist within the IT platform so resources are not wasted by SBUs as they seek to build IT support for their business strategies. In this case, SBU-based resources and capabilities can be better spent aligning IT around those unique activities that the SBU regards as a differentiator. Therefore, MBOs' efforts to build corporate IT platforms and improve IT alignment at the corporate level can make it easier for SBUs to support idiosyncratic activities needed to execute their business strategies. Moreover, if the level of SBU IT alignment is high, the SBU may be able to use its local knowledge and its success with using local IT to quickly respond to market-based threats and opportunities [40].

Accordingly, we propose that the positive impacts of corporate IT alignment on SBU performance depend on the degree of SBU IT alignment. An SBU is more likely to spot opportunities and threats in its environment when the level of IT support to the SBU strategy is satisfactory - i.e., when SBU IT alignment is high. Thus, corporate IT alignment and SBU IT alignment interact and reinforce each other in that they jointly ensure IT support for corporate-wide activities and idiosyncratic SBU activities. This leads to our first hypothesis:

\section{H1: The complementarity of corporate IT alignment and SBU IT alignment has a significant positive effect on $S B U$ performance.}

While the individual components of a complementary relationship can have individual effects on firm performance [42], neither corporate IT alignment nor SBU IT alignment individually will provide the level of IT support MBOs need to enable both common and idiosyncratic business activities [10, 32]. A coordinated effort to build IT alignment in
MBOs and leverage IT complementarities between corporate units and SBUs is more likely to lead to higher SBU performance. Thus:

\section{H2: The complementarity of corporate IT alignment and SBU IT alignment is a stronger predictor of SBU performance than either corporate IT alignment or SBU IT alignment individually.}

\section{Methodology}

A field survey of 120 organizations was conducted to test our hypotheses. The sampling frame included 1,200 organizations with 800 selected from the U.S. and 400 from Australia and Germany. These firms were identified in S\&P Compustat, Australian Securities Exchange, and contact lists maintained by researchers at MIT CISR and Bamburg University. The survey was administered in 2012. We identified a Chief Information Officer (CIO) familiar with the key market-facing SBU as our key informant. CIOs are appropriate informants for IT alignment studies [21]. They are sufficiently knowledgeable to answer questions about the corporate unit and key SBUs because of their participation in IT investment decisions that affect SBUs and reporting relationships in MBOs that facilitate CIOs' understanding of the IT needs and performance of key market-facing SBUs.

Our survey generated 141 responses (an initial response rate of $12 \%$ ) and of those responses twentyone were excluded due to missing data. Therefore, our final sample of 120 organizations yields a response rate of $10 \%$. While low, this is on par with survey response rates reported elsewhere in the IT alignment literature where respondents are senior IT executives [2, 13, 26].

The participating organizations come from the U.S. (42\%), Germany (40\%), and Australia (18\%). They represent a variety of industries including financial services, electronics, manufacturing, retail, energy, and logistics. On average, respondents had been in their current role for eight years and had worked at the same organization for 12 years.

\subsection{Survey Measures}

All key constructs in our study were measured using multi-item 5-point Likert type scales. The survey was refined using feedback from pilot tests with IT executive sponsors of member firms of MIT CISR. The scale items are shown in Appendix A.

Existing literature employs both direct and indirect measures to assess IT alignment $[8,31]$. The indirect approach is based on separate assessments of IT and 
business strategy. Contingency fit methods such as profile deviation and moderation are then used to calculate alignment [31]. The direct approach is based on measurement scales to ascertain the perceived extant of IT alignment [30]. Prior research shows that both types of measures are robust for testing the effects of IT alignment $[8,31]$.

Consistent with existing IT alignment studies [e.g., $13,19,20,21,30]$, we use measures that directly capture the state of IT alignment. Specifically, we assess the extent of corporate IT alignment on the basis of whether the corporate IT platform supports the corporate strategy. Similarly, we assess the extent of SBU IT alignment on the basis of whether the SBU IT application portfolio supports the SBU strategy [32]. In line with prior research that operationalizes complementarity using interaction terms [33, 38, 45], we measure IT alignment complementarity in MBOs as the interaction between the two types of IT alignment (corporate IT alignment $x$ SBU IT alignment).

To measure SBU performance, we use a series of items taken from Powell and Dent-Micallef [29] and Kim et al. [22]. These perceptual items assess market share, revenues, revenue growth, and profitability relative to competitors. This approach is consistent with previous alignment studies investigating relative measures of performance [2, 6, 35]. In addition, as discussed in Appendix B, we collected archival performance data from S\&P Compustat - notably return on assets (ROA), return on equity (ROE), and profit data - for a three-year period and used that data to cross-validate our measure of SBU performance.

Control variables were used to account for differences in SBU contribution to firm revenue, SBU size, SBU IT autonomy, country of origin, and industry type. SBU size was operationalized as the log of the number of employees. IT autonomy assessed the sources of IT support (i.e., corporate IT or local SBU IT) for processes in the value chain.

\section{Analysis and Results}

\subsection{Measurement Model Assessment}

We conducted various tests to assess validity and reliability of our constructs. Correlations, composite reliability, and average variance extracted (AVE) are summarized in Table 1 . We first reviewed construct-toitem loadings. All items load more highly on their own constructs and are significant at $p<0.001$. To assess internal consistency, we next examined measures of composite reliability for each construct. Composite reliability measures for each construct exceed 0.80 . In order to assess discriminant validity, we examined AVE and correlations among our constructs. The diagonal elements in Table 1 represent the square root of EVE and exceed the off-diagonal elements in the correlation matrix.

Multicollinearity among constructs is also an important validity concern since very high correlations can produce unstable estimates. This concern is particularly prevalent in studies testing complementarity effects because the components of a complementary relationship co-vary and therefore are expected to correlate. We performed collinearity tests and the results of those tests reveled minimal collinearity with all variance inflation factors (VIF) below 2.1. Together, these results suggest that our measures are valid and reliable.

\subsection{Hypotheses Testing}

We used regression analysis to test our research hypotheses. All multi-item measures were transformed into summated scales. In addition, the measures used in interaction terms were mean centered to mitigate multicollinearity problems. Table 2 presents the results of our hierarchical regression analysis.

As shown in Table 2 (Model 3), complementarity of corporate IT alignment and SBU IT alignment has a significant positive effect on SBU performance $(b=$ $0.20 ; p<0.05)$. Our results show a significant increase in $\mathrm{R}^{2}$ due to the interaction $\left(\Delta \mathrm{R}^{2}=0.032 ; p<0.05\right)$. Thus, H1 is supported. Figure 1 illustrates how the effects of corporate IT alignment vary as a function of SBU IT alignment.

The results of our analysis in Table 2 also show that neither corporate IT alignment nor SBU IT alignment individually affect SBU performance. We examined these relationships before and after accounting for the effects of complementarity (Models 2 and 3, respectively). The results confirm that

Table 1. Validity and reliability statistics and correlations between constructs

\begin{tabular}{|l|c|c|c|c|c|c|}
\hline Research Constructs & CR & AVE & $\mathbf{1}$ & $\mathbf{2}$ & $\mathbf{3}$ & $\mathbf{4}$ \\
\hline 1. Corporate IT alignment & 0.81 & 0.55 & $\mathbf{0 . 7 6}$ & & & \\
\hline 2. SBU IT alignment & 0.82 & 0.55 & 0.63 & $\mathbf{0 . 7 4}$ & & \\
\hline 3. SBU IT autonomy & 0.92 & 0.71 & -0.39 & -0.34 & $\mathbf{0 . 7 1}$ & \\
\hline 4. SBU performance & 0.91 & 0.66 & 0.26 & 0.25 & -0.22 & $\mathbf{0 . 8 2}$ \\
\hline $\begin{array}{l}\text { Notes: CR = Composite Reliability; The bold numbers on the diagonal are the square } \\
\text { root of the AVE; Off-diagonal elements are correlations between each pair of constructs. }\end{array}$
\end{tabular}


Table 2. Results of regression analysis

\begin{tabular}{|c|c|c|c|}
\hline Variable & $\begin{array}{l}\text { Model } 1 \\
\text { Controls }\end{array}$ & $\begin{array}{c}\text { Model } 2 \\
\text { Main Effect }\end{array}$ & $\begin{array}{c}\text { Model } 3 \\
\text { Full Model }\end{array}$ \\
\hline \multicolumn{4}{|l|}{ Controls } \\
\hline SBU size & $0.11^{\mathrm{N} / \mathrm{S}}$ & $0.10^{\mathrm{N} / \mathrm{S}}$ & $0.12^{N / S}$ \\
\hline SBU contribution to firm revenue & $0.08^{N / S}$ & $0.07^{\mathrm{N} / \mathrm{S}}$ & $0.07^{\mathrm{N} / \mathrm{S}}$ \\
\hline SBU IT autonomy & $-0.17^{\mathrm{N} / \mathrm{S}}$ & $-0.10^{\mathrm{N} / \mathrm{S}}$ & $-0.13^{\mathrm{N} / \mathrm{S}}$ \\
\hline Industry type & $0.05^{\mathrm{N} / \mathrm{S}}$ & $0.04^{\mathrm{N} / \mathrm{S}}$ & $0.05^{\mathrm{N} / \mathrm{S}}$ \\
\hline Country of origin & $-0.09^{N / S}$ & $-0.11^{\mathrm{N} / \mathrm{S}}$ & $-0.10^{\mathrm{N} / \mathrm{S}}$ \\
\hline \multicolumn{4}{|l|}{ Main Effects } \\
\hline Corporate IT alignment & & $0.10^{N / S}$ & $0.14^{\mathrm{N} / \mathrm{S}}$ \\
\hline SBU IT alignment & & $0.11^{\mathrm{N} / \mathrm{S}}$ & $0.14^{\mathrm{N} / \mathrm{S}}$ \\
\hline \multicolumn{4}{|l|}{ Interaction } \\
\hline Corporate IT alignment x SBU IT alignment & & & $0.20^{*}$ \\
\hline $\mathrm{R}^{2}$ & $6.1 \%$ & $9.5 \%$ & $12.7 \%$ \\
\hline$\Delta \mathrm{R}^{2}$ & & $0.034^{\dagger}$ & $0.032^{*}$ \\
\hline
\end{tabular}

complementarity of corporate IT alignment and SBU IT alignment is a stronger predictor of SBU performance than either type of alignment individually. Thus, $\mathrm{H} 2$ is supported.

\section{Discussion}

Recognizing the growing prevalence of MBOs and a dearth of IT alignment research in these organizations, this study raises an important question: how do corporate IT alignment and SBU IT alignment - individually and jointly - affect SBU performance in MBOs? Our results reveal that these two types of IT alignment are complementary and that they have joint positive effects on SBU performance. This finding hints at the need for IT managers in MBOs to forge a

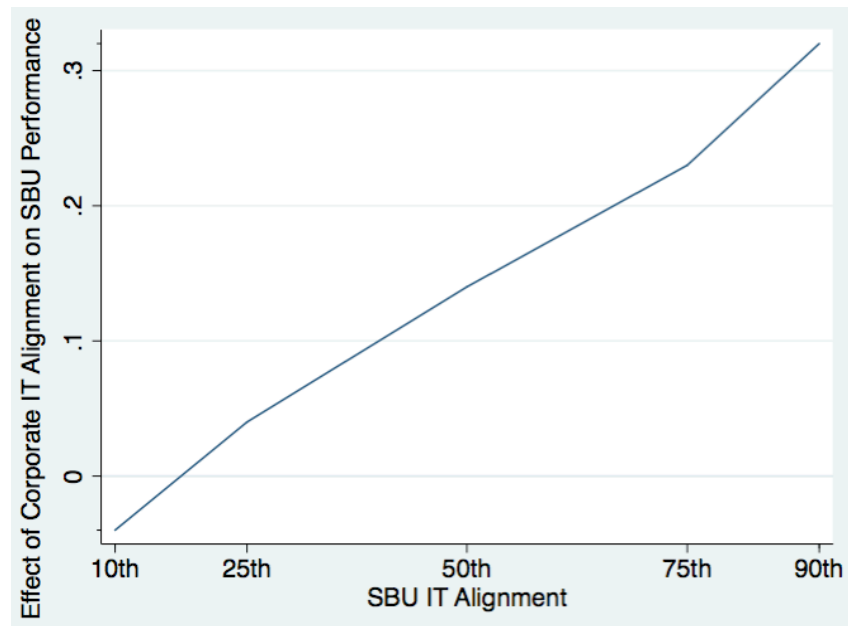

Note: SBU IT alignment values are the $10^{\text {th }}$ to $90^{\text {th }}$ data percentiles.

Figure 1. Effect of corporate IT alignment on SBU performance as a function of SBU IT alignment close working relationship between the corporate unit and SBUs in terms of orchestrating consistent IT support for all SBU activities.

To the extent that MBOs invest in corporate IT platform capabilities to support the corporate strategy, best practices around corporate IT alignment can spillover to SBUs. So, even if business strategies are different at the corporate and SBU levels, the knowledge of how to achieve and maintain IT alignment is likely to be shared across the organization. This likely reflects the fact that corporate units endeavor to build synergies across SBUs in order to minimize IT duplication, increase IT standardization, and achieve economies of scale [42]. Thus, corporate engagement is key to allowing SBUs to excel at what they do best: using local knowledge and dedicated IT resources to meet a set of specified product-market needs $[16,17]$.

\subsection{Contributions of the Research}

Our study contributes to the IT alignment literature in two ways. First, a tiny fraction of research in the IT alignment domain has looked at IT alignment in SBUs. In MBOs, both corporate IT alignment and SBU IT alignment are important and neither can be ignored because of potential path dependencies and complementarities [32]. As such, our study of different types of IT alignment in MBOs is an important step forward in our understanding of IT alignment and its impacts to SBU performance. To ignore the growing utilization of corporate IT platforms in MBOs and just focus on corporate IT alignment undermines the importance of local IT alignment within SBUs and the role of corporate IT in driving SBU performance. 
Second, we integrate insights from the literatures on IT alignment and resource complementarities to theorize that different types of IT alignment in MBOs are complementary and have joint effects on SBU performance. We find that complementarity of corporate IT alignment and SBU IT alignment has a positive effect on SBU performance. By exploring the complementarity effects of IT alignment in MBOs, we also gained insights into the conditions under which IT alignment does and does not impact performance. In particular, we find that neither corporate IT alignment nor SBU IT alignment individually drive SBU performance. Thus, our findings highlight the need for MBOs to pursue coherent IT investments in corporate IT and local SBU IT in order to build alignment at both the corporate and SBU levels.

With regard to the role of corporate IT management in enabling SBU performance, it is also important to highlight that corporate units face their own IT alignment problems first. To the extent that corporate IT executives succeed in meeting their own IT needs, they can turn their attention to optimizing how IT can meet the common needs of their diverse SBUs. A corporate IT unit that faces political and technical struggles - perhaps even resource constrains that undermine corporate IT alignment - is not going to be in a position to focus elsewhere. As corporate IT alignment improves, corporate IT managers can focus their resources on developing shared IT platform capabilities for SBUs without facing criticism from corporate business managers.

The fact that the corporate unit can have an impact on SBU performance though its effort to build corporate IT alignment is a reflection of how IT is evolving and how it is used within organizations. It is also, we believe, an indication that IT alignment may, in years to come, be more about how organizations tap IT to meet their unique IT needs if the provision of tactical IT support can be taken for granted. IT alignment may be less about commodity IT that, while still important, is not going to be a source of competitive advantage since these support needs can be quickly and efficiently satisfied through the development of a shared corporate IT platform.

\subsection{Implication for Practice}

CIOs continue to describe IT alignment as a foremost challenge. Understanding how to resolve this challenge means that we must first accept that MBOs are a primary organizational form and that IT alignment cannot be divorced from the organizational structure. For CIOs who face persistent IT alignment challenges, our research confirms that investing in corporate IT platform capabilities to enable the corporate strategy is central for building a base of IT support for market-facing SBUs. To some degree, SBUs face similar IT challenges that can be addressed through a combination of corporate IT and local IT. Where SBUs face unique IT challenges due to the nature of their products and markets, it makes sense to allow those SBUs to leverage shared IT but to then build on that by implementing their own unique IT solutions to support the SBU strategy. Certainly, some SBUs might resent the imposition of centralized IT control and the need to use a corporate IT platform to meet some of their IT needs, even if those needs are non-strategic. Our research shows that from an organizational perspective, it makes sense to package IT support for common business activities in a corporate IT platform but to still allow SBUs some autonomy to meet their idiosyncratic IT needs through local IT sources.

\subsection{Limitations and Future Research}

The findings from this study are subject to a number of limitations. We did not collect data from each and every SBU in each organization in our sample. It can be difficult to test all SBUs in an organization since financial accounting disclosure rules apply only to material SBUs that account for at least $10 \%$ of total sales or profits. Instead, we focused on the key market-facing SBU in each organization. It is possible that in so doing, we overlooked cross-unit synergies between SBUs that could potentially impact the flagship SBU. Future research could address this limitation. There is equally an unexplored time dimension in our research. Alignment takes time to mature and so future research could look at how and when the effects of corporate IT alignment are realized at the SBU level.

In addition, we did not examine different management practices that prior studies have found to affect IT alignment. Our measures of IT alignment, we believe, could be included in a nomological network that seeks to explain how corporate and SBU management practices help drive IT alignment in MBOs. Corporate-level practices could certainly remain important to IT alignment in MBOs but it is equally likely that other practices - embedded at lower levels of the organization - could play a key role in attempts to improve alignment at each level.

\section{Conclusion}

The IT alignment literature has made considerable progress in the decades since it began to attract interest from IT academics and practitioners. As the literature 
has progressed through different stages, researchers have assessed alignment and its implications at finer levels of granularity. From cross-referencing of business and IS plans to analyses of alignment at different dimensions at the corporate and process levels, we are now able to add one more layer of detail to the story by considering the complementarity effects of IT alignment in MBOs. Overall, our results allow us to extend our understanding of IT alignment and its effects on SBU performance. From this emerges an IT alignment paradigm that reflects the different types of IT alignment in MBOs and their joint effects on SBU performance. Applying this paradigm in future research will, we hope, help to resolve some of the concerns around IT alignment that continue to make it a pressing challenge for IT executives.

\section{References}

[1] R. Agarwal, and V. Sambamurthy, "Principles and Models for Organizing the IT Function", MIS Quarterly Executive, 1 (2002), pp. 1-16.

[2] F. Bergeron, L. Raymond, and S. Rivard, "Ideal Patterns of Strategic Alignment and Business Performance", Information \& Management, 41 (2004), pp. 1003-1020.

[3] W. F. Boh, and D. Yellin, "Using Enterprise Architecture Standards in Managing Information Technology", Journal of Management Information Systems, 23 (2007), pp. 163-207.

[4] C. V. Brown, "Horizontal Mechanisms Under Differing IS Organization Contexts", MIS Quarterly, 23 (1999), pp. 421-454.

[5] Y. E. Chan, "Why Haven't We Mastered Alignment? The Importance of the Informal Organization Structure", MIS Quarterly Executive, 1 (2002), pp. 97-112.

[6] Y. E. Chan, S. L. Huff, D. W. Barclay, and D. G. Copeland, "Business Strategic Orientation, Information Systems Strategic Orientation, and Strategic Alignment", Information Systems Research, 8 (1997), pp. 125-150.

[7] Y. E. Chan, R. Sabherwal, and J. B. Thatcher, "Antecedents and Outcomes of Strategic IS Alignment: An Empirical Investigation", IEEE Transactions on Engineering Management, 53 (2006), pp. 27-47.

[8] T. Coltman, P. Tallon, R. Sharma, and M. Queiroz, "Strategic IT Alignment: Twenty-five Years On", Journal of Information Technology, 30 (2015), pp. 91-100.

[9] S. De Haes, and W. Van Grembergen, "An Exploratory Study into IT Governance Implementations and Its Impact on Business/IT Alignment", Information Systems Management, 26 (2009), pp. 123-137.
[10] N. Fonstad, and M. Subramani, "Building Enterprise Alignment: A Case Study", MIS Quarterly Executive, 8 (2009), pp. 31-41.

[11] V. Gaba, and J. Joseph, "Corporate Structure and Performance Feedback: Aspirations and Adaptation in Mform Firms", Organization Science, 24 (2013), pp. 11021119 .

[12] J. E. Gerow, V. Grover, J. Thatcher, and P. L. Roth, "Looking Toward the Future of IT-Business Strategic Alignment through the Past: A Meta-Analysis", MIS Quarterly, 38 (2014), pp. 1059-1085.

[13] J. E. Gerow, J. B. Thatcher, and V. Grover, "Six Types of IT-business Strategic Alignment: An Investigation of the Constructs and Their Measurement", European Journal of Information Systems, 24 (2014), pp. 1-27.

[14] B. R. Golden, "SBU Strategy and Performance: The Moderating Effects of the Corporate-SBU Relationship", Strategic Management Journal, 13 (1992), pp. 145-158.

[15] D. Goodhue, D. Chen, M. C. Boudreau, and A. R. Davis, "Addressing Business Agility Challenges with Enterprise Systems", MIS Quarterly Executive, 8 (2009), pp. $73-88$.

[16] V. Gurbaxani, and S. Whang, "The Impact of Information Systems on Organizations and Markets", Communications of the ACM, 34 (1991), pp. 59-73.

[17] M. C. Jensen, and W. H. Meckling, Specific and General Knowledge, and Organizational Structure, in L. Werin and H. Wijkander, eds., Contract Economics, Blackwell, Oxford, 1992, pp. 251-274.

[18] J. Joseph, and W. Ocasio, "Architecture, attention, and adaptation in the multibusiness firm: General Electric from 1951 to 2001", Strategic Management Journal, 33 (2012), pp. 633-660.

[19] E. Karahanna, and D. S. Preston, "The Effect of Social Capital of the Relationship Between the CIO and Top Management Team on Firm Performance", Journal of Management Information Systems, 30 (2013), pp. 15-56.

[20] G. S. Kearns, and A. L. Lederer, "A Resource-Based View of Strategic IT Alignment: How Knowledge Sharing Creates Competitive Advantage", Decision Sciences, 34 (2003), pp. 1-30.

[21] G. S. Kearns, and R. Sabherwal, "Strategic Alignment between Business and Information Technology: A Knowledge-based View of Behaviors, Outcome, and Consequences", Journal of Management Information Systems, 23 (2007), pp. 129-162.

[22] G. Kim, B. Shin, K. K. Kim, and H. G. Lee, "IT Capabilities, Process-Oriented Dynamic Capabilities, and Firm Financial Performance", Journal of the Association for Information Systems, 12 (2011), pp. 487-517. 
[23] T. S. McLaren, M. M. Head, Y. Yuan, and Y. E. Chan, "A multilevel Model for Measuring Fit between a Firm's Competitive Strategies and Information Systems Capabilities", MIS Quarterly, 35 (2011), pp. 909-929.

[24] P. Milgrom, and J. Roberts, "Complementarities and Fit Strategy, Structure, and Organizational Change in Manufacturing", Journal of Accounting and Economics, 19 (1995), pp. 179-208.

[25] P. Milgrom, and J. Roberts, "The Economics of Modern Manufacturing: Technology, Strategy, and Organization", The American Economic Review, 80 (1990), pp. 511-528.

[26] W. Oh, and A. Pinsonneault, "On the Assessment of the Strategic Value of Information Technologies: Conceptual and Analytical Approaches", MIS Quarterly, 31 (2007), pp. 239265.

[27] A. Parmigiani, and S. S. Holloway, "Actions Speak Louder than Modes: Antecedents and Implications of Parent Implementation Capabilities on Business Unit Performance", Strategic Management Journal, 32 (2011), pp. 457-485.

[28] M. Porter, and N. Siggelkow, "Contextuality within activity systems and sustainability of competitive advantage", The Academy of Management Perspectives, 22 (2008), pp. 34-56.

[29] T. C. Powell, and A. Dent-Micallef, "Information Technology as Competitive Advantage: The Role of Human, Business, and Technology Resources", Strategic Management Journal, 18 (1997), pp. 375-405.

[30] D. S. Preston, and E. Karahanna, "Antecedents of IS Strategic Alignment: A Nomological Network", Information Systems Research, 20 (2009), pp. 159-179.

[31] M. Queiroz, "Mixed Results in Strategic IT Alignment Research: A Synthesis and Empirical Study", European Journal of Information Systems, 26 (2017), pp. 21-36.

[32] P. Reynolds, and P. Yetton, "Aligning Business and IT Strategies in Multi-Business Organizations", Journal of Information Technology, 30 (2015), pp. 101-118.

[33] R. G. Richey, P. J. Daugherty, and A. S. Roath, "Firm Technological Readiness and Complementarity: Capabilities Impacting Logistics Service Competency and Performance", Journal of Business Logistics, 28 (2007), pp. 195-228.

[34] J. Ross, P. Weill, and D. Robertson, Enterprise Architecture as Strategy: Creating a Foundation for Business Execution, Harvard Business School Press, Boston, MA, 2006.

[35] R. Sabherwal, and Y. E. Chan, "Alignment between Business and IS Strategies: A Study of Prospectors, Analyzers, and Defenders", Information Systems Research, 12 (2001), pp. 11-33.
[36] V. Sambamurthy, and R. W. Zmud, "Arrangements for Information Technology Governance: A theory of Multiple Contingencies", MIS Quarterly, 23 (1999), pp. 261-290.

[37] C. Sauer, and P. W. Yetton, Steps to the Future: Fresh Thinking on the Management of IT-based Organizational Transformation, Jossey-Bass Publishers, San Francisco, 1997.

[38] M. Song, C. Droge, S. Hanvanich, and R. Calantone, "Marketing and Technology Resource Complementarity: An Analysis of Their Interaction Effect in Two Environmental Contexts", Strategic Management Journal, 26 (2005), pp. 259-276.

[39] J. Strikwerda, and J. Stoelhorst, "The Emergence and Evolution of the Multidimensional Organization", California Management Review, 51 (2009), pp. 11-31.

[40] P. Tallon, and A. Pinsonneault, "Competing Perspectives on the Link Between Strategic Information Technology Alignment and Organizational Agility: Insights from a Mediation Model", MIS Quarterly, 35 (2011), pp. 463-486.

[41] H. Tanriverdi, "Information Technology Relatedness, Knowledge Management Capability, and Performance of Multibusiness Firms", MIS Quarterly, 29 (2005), pp. 311334.

[42] H. Tanriverdi, "Performance Effects of Information Technology Synergies in Multibusiness Firms", MIS Quarterly, 30 (2006), pp. 57-77.

[43] H. Tanriverdi, and N. Venkatraman, "Knowledge Relatedness and the Performance of Multibusiness Firms", Strategic Management Journal, 26 (2005), pp. 97-119.

[44] D. J. Teece, R. Rumelt, G. Dosi, and S. Winter, "Understanding Corporate Coherence: Theory and Evidence", Journal of Economic Behavior \& Organization, 23 (1994), pp. 1-30.

[45] S. Vickery, C. Droge, P. Setia, and V. Sambamurthy, "Supply Chain Information Technologies and Organisational Initiatives: Complementary versus Independent Effects on Agility and Firm Performance", International Journal of Production Research, 48 (2010), pp. 7025-7042.

[46] P. Weill, and J. W. Ross, IT Governance: How Top Performers Manage IT Decision Rights for Superior Results, Harvard Business School Press, Boston, 2004.

[47] P. Weill, M. Subramani, and M. Broadbent, "Building IT Infrastructure for Strategic Agility", MIT Sloan Management Review, 44 (2002), pp. 57-65.

[48] C. K. Williams, and E. Karahanna, "Causal Explanation in the Coordinating Process: A Critical Realist Case Study of Federated IT Governance Structures", MIS Quarterly, 37 (2013), pp. 933-964. 
[49] O. E. Williamson, The Economic Institutions of Capitalism: Firms, Markets, and Relational Contracting, MacMillan Free Press, New York, NY, 1985.

[50] S. Wu, D. Straub, and T.-P. Liang, "How Information Technology Governance Mechanisms and Strategic Alignment Influence Organizational Performance: Insights from a Matched Survey Of Business and IT Managers", MIS Quarterly, 39 (2015), pp. 497-518.

[51] K. Zhu, "The Complementarity of Information Technology Infrastructure and e-commerce Capability: A Resource-based Assessment of Their Business Value", Journal of Management Information Systems, 21 (2004), pp. 167-202.

\section{Appendix A. Survey Items \& Constructs}

Corporate IT Alignment (1: Strongly disagree; 5: Strongly agree)

To what extent do the following statements reflect the current situation in the MBO?

a. The corporate IT platform lacks capabilities that are necessary to enable the effective execution of the corporate strategy.

b. The organization is a long way short of where the corporate IT platform capabilities need to be to support the corporate strategy.

c. The potential of the corporate IT platform is not fully considered when corporate strategy decisions are made.

d. Overall, the corporate IT platform meets the needs of the corporate strategy.

SBU IT Alignment (1: Strongly disagree; 5: Strongly agree)

To what extent do the following statements reflect the current situation in the SBU?

a. The existing SBU IT application portfolio lacks capabilities that are necessary to effectively execute the SBU strategy.

b. The existing SBU IT application portfolio provides sufficient support for the execution of our SBU strategy.

c. The potential of the SBU IT application portfolio is not fully considered when SBU strategy decisions are made.

d. Overall, the SBU IT application portfolio meets the needs of the SBU strategy.
SBU Performance (1: Strongly disagree; 5: Strongly agree)

To what extent do the following statements reflect the current situation in the SBU?

a. We are more profitable than our competitors.

b. Our sales growth exceeds that of our competitors.

c. Our revenue growth exceeds that of our competitors.

d. Our market share growth exceeds that of our competitors.

e. Overall, our performance is better than our competitors.

SBU IT Autonomy (1: Corporate IT platform only; 3: Equally by SBU \& corporate IT platform; 5: SBU only)

Please indicate the sources of IT application support for the following business processes.

a. Supplier relations.

b. Product/service operations.

c. Product/service enhancement.

d. Sales and marketing.

e. Customer relations.

\section{Appendix B. Cross-Validation of SBU Performance Data with Archival Firm Performance Data}

We compared our self-reported SBU performance data with archival firm performance data collected from S\&P Compustat for 61 publicly traded firms in our sample. Specifically, we collected data on profit margin, return on assets (ROA), and return on equity (ROE) for a three-year period - 2010 to 2012 (the year of the survey) - and computed average performance scores as a way to reduce the effects of performance variations over this period. Then, we created a summated scale using this data and performed a correlation analysis to assess the association between SBU performance and firm performance. Our results show a significant correlation between SBU performance and the measure of firm performance $(0.29, p<0.05)$. 